\title{
ATIVIDADES EMPREENDEDORAS DE ALUNOS DE GRADUAÇÃO EM CIÊNCIAS SOCIAS APLICADAS: MAPEAMENTO EM UMA UNIVERSIDADE PRIVADA COMUNITÁRIA
}

Bruno Da Silva Goes ${ }^{1}$

João Paulo Moreira Silva ${ }^{1}$

Liliane De Oliveira Guimarães ${ }^{1}$

Paula Karina Salume ${ }^{1}$

${ }^{1}$ Pontifícia Universidade Católica de Minas Gerais - PUC Minas 


\title{
ATIVIDADES EMPREENDEDORAS DE ALUNOS DE GRADUAÇÃO EM CIÊNCIAS SOCIAS APLICADAS: MAPEAMENTO EM UMA UNIVERSIDADE PRIVADA COMUNITÁRIA
}

\begin{abstract}
RESUMO
Este trabalho teve por objetivo levantar e classificar as iniciativas empreendedoras dos alunos de graduação do Instituto de Ciências Econômicas Gerenciais de uma universidade privada comunitária de Belo Horizonte. Intenciona-se criar um banco de dados que permita acompanhar a trajetória dos egressos e planejar ações acadêmicas mais assertivas para formação empreendedora dos alunos. Aplicou-se um questionário em 549 alunos, o que representa 30\% dos estudantes do referido instituto. Constatou-se que os alunos do turno diurno desenvolvem mais atividades empreendedoras do que os do noturno. Por outro lado, os alunos do turno noturno, em maior frequência, apresentam vínculo com atividades formais remuneradas. No caso dos alunos que empreendem, as atividades relacionadas ao comércio e/ou prestação de serviços são predominantes. Essa condição é semelhante ao encontrado no empreendedorismo em nível nacional, inferindo-se que são negócios que apresentam baixas barreiras à entrada, não exigindo alto volume de capital e outros recursos.
\end{abstract}

Palavras chave: Atividades empreendedoras. discentes. universidade privada comunitária. alunos de graduação.

\section{INTRODUÇÃO}

No segundo semestre de 2017, foi realizado um projeto de pesquisa cujo tema versou sobre universidade empreendedora. O objetivo foi analisar, sob a ótica discente, as estruturas e iniciativas de estímulo ao empreendedorismo desenvolvidas por diferentes Instituições de Ensino Superior de Belo Horizonte. A pesquisa foi realizada em oito instituições de ensino superior e os resultados permitiram elaborar o artigo "Universidade Empreendedora: análise de estruturas e iniciativas de estímulo ao empreendedorismo no ensino superior" (Salume, Guimarães, Junqueira \& Rodrigues, 2019).

Dentre os vários resultados obtidos com a pesquisa de 2017/2018 destaca-se que há muito a ser feito para que os alunos percebam o envolvimento docente e da alta administração universitária no apoio e no estímulo ao empreendedorismo discente (Chen, Hsiao, Cheng, Chou, Chen \& Shen, 2015; Gibb, 2002; Moreira-Silva, Guimarães, Inácio Júnior \& Castro, 2019). Evidenciou-se ainda que o processo de desenvolvimento de mentalidade empreendedora nos discentes não é consequência de esforço individual do docente ou da instituição, mas representa esforço conjunto dos atores institucionais, inclusive do próprio engajamento do aluno, que pela pesquisa inicial, mostrou-se ínfimo. Essas constatações referem-se ao grupo de Instituições pesquisadas e não dizem respeito às características específicas da instituição $\mathrm{A}$ ou $\mathrm{B}$ (Salume et al., 2019).

A taxa de novos empreendedores no Brasil é considerada muito baixa, 1,7\% em 2018, 4,4\% em 2017 e ao analisar as atividades empreendedoras de estágio inicial no Brasil, o perfil 
de idade com maior participação é de 18 a 24 anos, conforme a idade aumenta, a participação diminui (Bosma \& Kelley, 2019).

Bosma e Kelley (2019) afirmam que a redução da taxa de novos empreendedores pode ter sido causada pelo aumento da taxa de emprego formal, ou seja, o brasileiro vê o empreendedorismo como uma alternativa ao desemprego e não como um projeto profissional. Além disso, as opções de trabalho em grandes organizações são sinônimo de sucesso profissional no país (Arruda, Nogueira, Cozzi \& Costa, 2015). São, portanto, necessárias mudanças políticas que incentivem o empreendedorismo.

Apesar de o jovem ser o maior interessado em novos empreendimentos, o incentivo ao desenvolvimento de competências para empreender é muito baixo, principalmente por parte das universidades que tem ainda um foco acadêmico e não profissional. O Serviço Brasileiro de Apoio às Micro e Pequenas Empresas [SEBRAE], em parceria com a Endeavor (2016), identificou que apenas $38,78 \%$ das universidades oferecem cursos de formação empreendedora e somente $6,2 \%$ analisam profundamente o problema, além de que apenas $6,3 \%$ dos professores procurarem se atualizar com profissionais atuantes do mercado. Em contrapartida, 56\% dos alunos estão interessados em ter acesso a disciplinas relacionadas ao empreendedorismo.

A constatação de que os alunos não reconhecem a existência de estruturas universitárias e esforços docentes para estimular iniciativas empreendedoras conjugados aos dados que apontam taxas pequenas de novos empreendedores no Brasil (SEBRAE, 2016; Moreira-Silva et al., 2019) foi fator de motivação para a realização da presente pesquisa, que teve o intuito de levantar e classificar as expectativas e atuação em atividades empreendedoras dos alunos de graduação do Instituto de Ciências Econômicas e Gerenciais (ICEG) de uma universidade privada comunitária localizada em Belo Horizonte - MG. Esse é o primeiro passo para criar um banco de dados que permita acompanhar a trajetória dos egressos, desenvolver mecanismos de apoio mais evidentes às atividades empreendedoras docentes e planejar ações acadêmicas mais assertivas para formação profissional e empreendedora dos alunos. Vale ressaltar que os resultados aqui expostos representam parte dos dados obtidos e que, a pesquisa, encontra-se em desenvolvimento.

Além dessa introdução, o artigo, na seção 2, apresenta o referencial teórico utilizado como base para definição dos objetivos e interpretação dos dados. Na seção 3 descrevemos a metodologia utilizada no trabalho e, na seção 4, a análise dos resultados. Por fim, na seção 5, apresentamos as principais conclusões do trabalho.

\section{REFERENCIAL TEÓRICO}

\subsection{Processo empreendedor}

O empreendedorismo é considerado um fator importante para a criação e desenvolvimento de negócios, assim como para a prosperidade de nações (Feldman, 2014; Lago, 2012; Leite, 2017; Hisrich, Peters \& Shepherd, 2014; Monteiro, 2010). A atividade de empreender - situação na qual novos bens e serviços são introduzidos no mercado - exige decisões e ações nem sempre fácil de serem tomadas (Hisrich et al., 2014). O empreendedor segue o que acredita ser uma oportunidade em um ambiente de incerteza, utilizando o seu discernimento para decidir se deve ou não agir (Hisrich et al., 2014). Em território nacional, o estudo realizado por Figueira, Horbe, Vargas, Machado e Moura (2017) observando startups do interior do estado do Rio Grande do Sul, constatou que, de modo geral, a motivação dos entrevistados para a abertura do negócio foi que, com base em problemas vivenciados no dia a 
dia, eles identificaram uma oportunidade de negócio. Isso os levou a investir na ideia de solução e os motivou à abertura de suas startups.

Além das condições do contexto econômico, político e social nem sempre percebidos como favorável à criação de empresas, existem as questões de ordem individual, ou seja, a maior ou menor prevalência de características empreendedoras no potencial empreendedor. Segundo Sarkar (2010), os traços empreendedores são mais prevalentes em alguns indivíduos, no entanto, o empreendedorismo poderá ser promovido através do apoio e da consolidação de uma cultura empreendedora (Isenberg, 2011; Spigel, 2013). A Figura 1 demonstra justamente tal situação: o círculo menor representa as pessoas com características consideradas "inatas", o segundo círculo as pessoas que podem ser influenciadas pela educação e cultura e o terceiro círculo as que não demonstrarão interesse em empreender.

Figura 1. Distribuição de empreendedores na sociedade

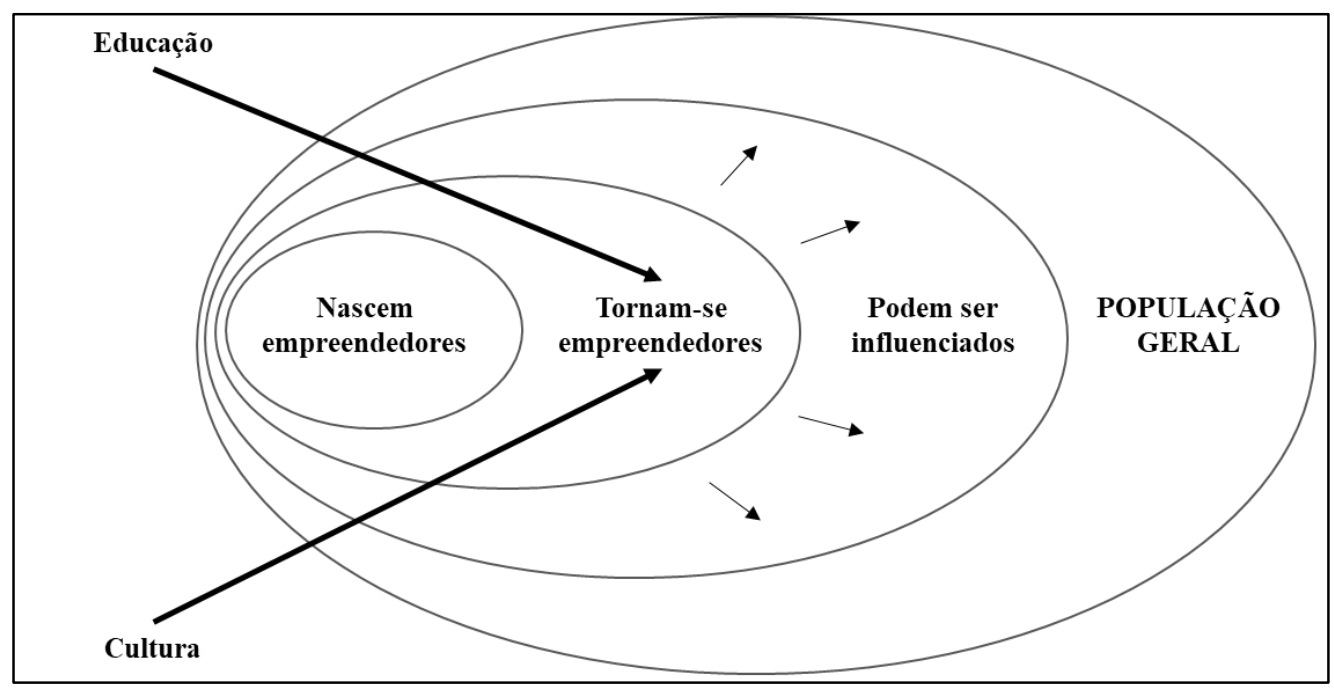

Fonte: Sarkar (2010, p.76)

Ainda analisando os aspectos individuais, mas considerando dessa vez também os coletivos, temos a pesquisa de Paiva, Lima, Rebouças, Ferreira e Fontenele (2018). Em seu estudo foi analisada a influência de alguns constructos, como por exemplo o comportamento sustentável, comportamento inovador e o País de origem, na intenção empreendedora dos estudantes universitários brasileiros e portugueses. O comportamento sustentável é apresentado, nesse caso, a partir da preocupação do indivíduo com questões ambientais e consequentemente com as questões sociais.

De acordo com os resultados, as variáveis que predizem a Intenção Empreendedora (IE) são: mobilização; adequação à originalidade; preferência pela mudança; familiares próximos empreendedores; universidade; gênero (masculino) e os primeiros semestres da universidade. Durante a pesquisa, a experiência profissional não demonstrou ter relação positiva à intenção empreendedora (Paiva, Lima, Rebouças, Ferreira \& Fontenele et al., 2018).

No caso específico das universidades, as habilidades empreendedoras podem ser estimuladas de diferentes formas, como os cursos em grade curricular (SEBRAE, 2016); extracurriculares (Tornatzky \& Rideout, 2014); incubadoras (Plonsky, 1999) e outros. Entretanto, o debate sobre o ensino empreendedor pelas universidades ainda persiste (Chen et 
al., 2015). Atualmente, o foco recai sobre o conhecimento prático instruído através da realização de projetos, que poderiam fomentar a formação de estudantes com mentalidade empreendedora (Premand, Brodmann, Almeida, Grun \& Barouni, 2016). Adicionalmente ao tipo de curso ou treinamento empreendedor, cabe ressaltar que conhecimentos em gestão tendem a elevar o desempenho dos empreendimentos (Ganotakis, 2012) e contribuem para o crescimento dos mesmos em nível nacional (Machado, 2018).

\subsection{Empreendedorismo de Base Tecnológica: startups}

A discussão sobre empresas de base tecnológica ou startups teve início na década de 90 , após a busca pela compreensão do sucesso das indústrias de semicondutores no Vale do Silício (Saxenian, 1990) Culminando, no início do século XXI, no que foi denominado de "bolha das ponto com", período fortemente caracterizado pela alta das ações das novas empresas de tecnologia da informação e comunicação com enfoque na internet (World Bank Institute [WBI], 2007; Kleina, 2017)

A compreensão do que seriam as "startups", apresenta variações. No entanto, uma definição atual e que se tornou mais aceita por investidores e especialistas é aquela proposta por Blank (2010), que considera as startups como "um grupo de pessoas à procura de um modelo de negócios repetível e escalável, trabalhando em condições de extrema incerteza." (Associação Brasileira de Startups [ABStartups], 2017, p.1). Em outras palavras, as empresas classificadas como startups são aquelas que apresentam uma forma de operação e geração de valor que possa ser repetida diversas vezes aferindo ganhos de escala e que estejam envoltos em um contexto de incertezas, comum no cenário tecnológico. Um negócio tradicional ou de base tecnológica só será considerada uma startup se cumprir as características constitutivas mencionadas anteriormente (ABStartups, 2017).

Em um mundo globalizado, repleto de incertezas, as startups vêm se tornando muito conhecidas, principalmente devido à visibilidade adquirida pelo desenvolvimento tecnológico e econômico que elas podem proporcionar (Henrekson \& Johansson, 2010; Pinochet, 2018). Segundo Figueira et al. (2017), startups representam um modelo de negócio conhecido por ser inicialmente pequeno e apresentar poucos recursos. Com a escassez de recursos, essas empresas precisam de investimentos e incentivos para que possam se desenvolver (Antonenko, Lee \& Kleinheksel, 2014; Torres \& Souza, 2016; Pinochet, 2018 apud Fonseca, Lopez-Garcia \& Pissarides, 2001).

No Brasil, estima-se que existam cerca de 6 mil startups, sendo 5147 efetivamente cadastradas pela ABStartups em 2017 (Brito, 2017). Dentre os ecossistemas mais relevantes, é possível citar os estados de São Paulo, Minas Gerais e Santa Catarina (Carvalho, 2018; Escobar, 2019). Os três estados são reconhecidos como os três primeiros em número de startups criadas. Quando os indicadores são sobre densidade de startups, os três estados ainda figuram nas quatro primeiras posições, com o acréscimo do Distrito Federal como segundo colocado. Entretanto, e apesar dos bons sinais no desenvolvimento e aumento de startups, a taxa de mortalidade de startups brasileiras é elevada, com valores de até $75 \%$, sendo o motivo mais comum o conflito entre sócios (Rosa, 2018).

Entretanto, os resultados mostraram que o processo de criação de uma startup não é rápido, e nem ocorre ao acaso (Figueira, Horbe, Vargas, Machado \& Moura, 2017; MoreiraSilva et al., 2019). Os empreendedores levam de quatro a seis meses para formular a ideia do negócio e colocá-la em prática. Gestores de startups não usam apenas metodologias de gestão específicas, mas também ferramentas de gestão tradicionais como o plano de negócios. Figueira 
et al. (2017) ainda revela que os principais problemas das startups são a falta de recursos financeiros, falta de conhecimento de gestão, dificuldade de aceitação de clientes e excesso de burocracia dos órgãos.

\subsection{Empreendedorismo sustentável}

O empreendedorismo sustentável é reconhecido como um objeto de pesquisa recente e em expansão, com definições ainda em processo de construção (Boszczowski \& Teixeira, 2012). Quando vinculado à atividade econômica, o empreendedorismo sustentável é tido como "o reconhecimento, desenvolvimento e exploração de oportunidades por indivíduos na criação de futuros produtos e serviços com ganhos econômicos, sociais e ecológicos" (Belz \& Binder, 2015, p.2). Segundo Cohen \& Winn (2007), o empreendedorismo sustentável pressupõe a discussão das consequências ambientais perpetradas pelos empreendedores, coresponsabilizando-os (Jacobi, 2003), em consonância com os critérios de desenvolvimento sustentável institucionalizados - um desenvolvimento que atenda às necessidades do presente sem comprometer a habilidade das gerações futuras em atender às suas próprias necessidades (World Commission on Environment and Development [WCED], 1987). Os empreendedores sustentáveis são caracterizados também por utilizarem de imperfeições de mercado, como monopólios, assimetria de informações e externalidades negativas como oportunidades de negócio, gerando ganhos sociais e ambientais a sociedade ao mesmo tempo que geram ganhos econômicos ao empreendimento (Cohen \& Winn, 2007). Essa condição é conhecida como triple bottom line (Dixon \& Clifford, 2007)

A tenra literatura que discute o empreendedorismo sustentável busca também traçar as características empreendedoras de seus fundadores nesse tipo de negócio (Belz \& Binder 2015; Gast, Gundolf \& Cesinger, 2017). Até o momento, é possível destacar que as características pessoais terão relevância ainda maior no caso de um empreendimento sustentável, dado ao fato dos negócios sustentáveis serem fundamentados nas visões de mundo e valores de seus empreendedores (Belz \& Binder, 2015), que buscam o desenvolvimento sustentável de comunidades ao seu redor (Boutillier, 2017; Gast et al., 2017).

Segundo Belz e Binder (2015), é possível compreender o processo empreendedor sustentável como um fluxo convergente, onde inicialmente os empreendedoras buscam os pressupostos econômicos e ecológicos dos empreendimentos, ou, aqueles sociais e econômicos, para posteriormente adicionarem o terceiro elemento ausente, evidenciando a ainda linha tênue entre o empreendedorismo sustentável e o social (Dees, 1998; Gast et al., 2017). Conforme poderá ser visualizado na Figura 2 a seguir, o terceiro elemento poderá ser o tripé social ou o ecológico, a depender das escolhas iniciais. 
Figura 2 - Processo de empreendedorismo sustentável

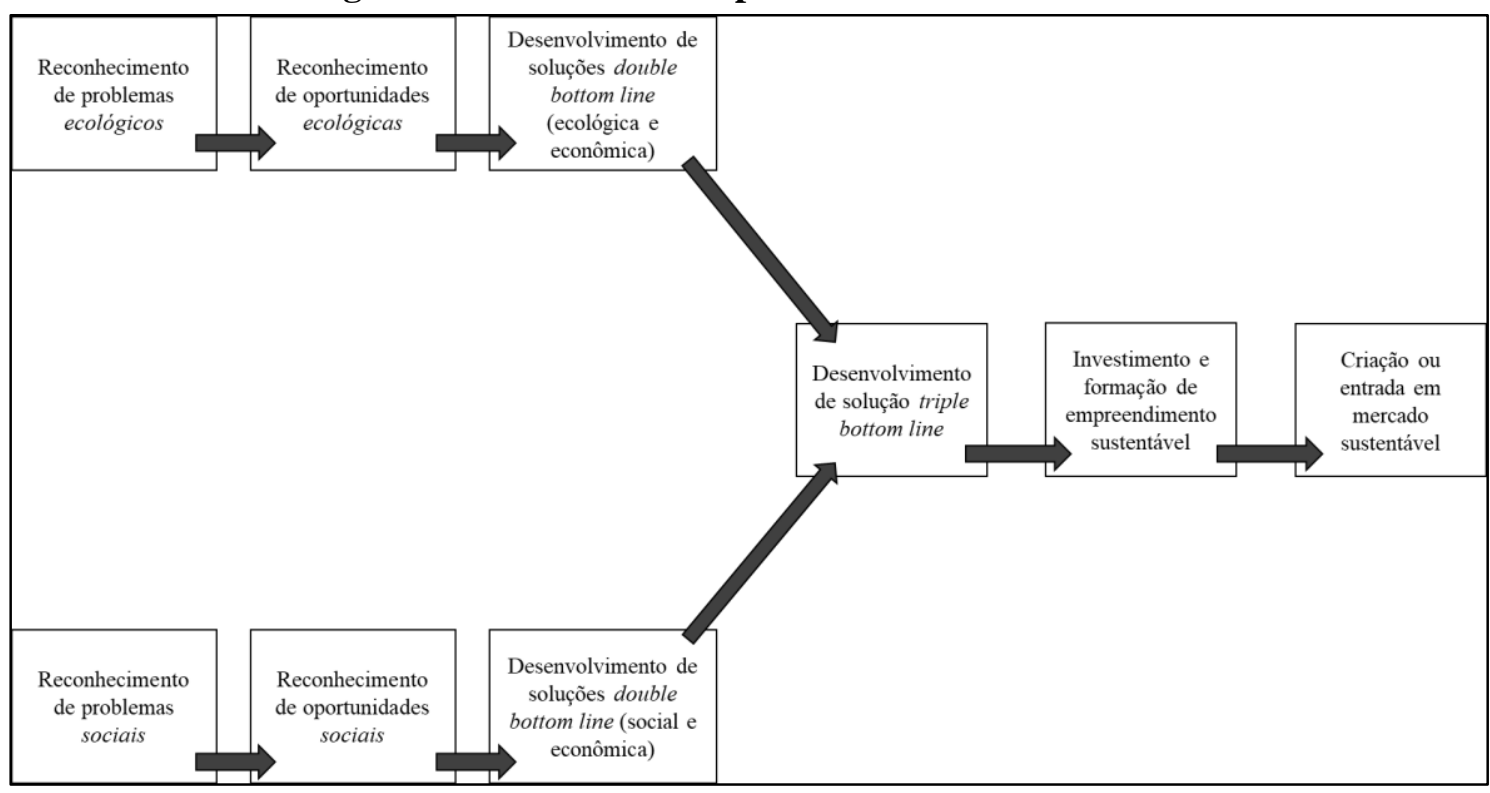

Fonte: Belz e Binder (2015)

De toda forma, o empreendedorismo sustentável encontra inúmeras dificuldades em seu desenvolvimento, sejam elas financeiras, de produção ou de mercado (Gast et al., 2017). Dificuldades estas que poderão até mesmo desestimular os empreendedores a buscarem suas aspirações e identificarem seus empreendimentos com seus valores (Pacheco et al., 2010). Cabe destacar que a universidade também terá papel fundamental no desenvolvimento não somente nas aspirações empreendedoras de viés sustentável, mas também em seu fortalecimento, definindo reflexões e projetos que tenham como objetivo a discussão do futuro social e ambiental das regiões e países (Cohen, 2006; Gast et al., 2018).

\section{METODOLOGIA}

A metodologia é o estudo dos métodos usados na realização de uma pesquisa, variando de acordo com as diferenças entre eles (Gil, 2002). Os motivos que levam um indivíduo a pesquisar são variados, sendo os principais na ordem de razão intelectual e prática (Gil, 2002).

Da Silva (2007, p.142) divide o processo de pesquisa em dois tipos, qualitativo e quantitativo. Para o autor, "o método quantitativo envolve coletar e analisar dados numéricos e aplicar testes estatísticos. O qualitativo é mais subjetivo e envolve examinar e refletir sobre as percepções para obter um entendimento de atividades sociais e humanas".

Considerando os objetivos da nossa pesquisa - levantar e classificar as atividades empreendedoras dos alunos de graduação em Ciências Sociais Aplicadas -, foram aplicados questionário nos alunos do ICEG de uma universidade privada comunitária, localizada em Belo Horizonte, Minas Gerais, buscando-se identificar e diagnosticar os negócios - formais e informais - desenvolvidos por esses alunos.

O ICEG apresenta um total de 1886 alunos matriculados, sendo 772 do turno matutino e 1114 do noturno. Quando considerada a divisão por cursos, 779 alunos são do curso de Administração, 595 de Ciências Contábeis e 512 de Economia. A amostra que preencheu os questionários foi de 549 alunos, aproximadamente $30 \%$ dos estudantes. Dos 549 questionários, 301 foram respondidos por alunos do turno matutino e 248 do noturno. Quando considerada a 
divisão por cursos, são 246 alunos oriundos do curso de Administração, 152 de Economia e 151 de Ciências Contábeis.

Na pesquisa, foi considerado a interpretação do estudante sobre o que ele identificava como emprego formal e empreendedorismo. Baseado nas informações respondidas pelos alunos, foram elaborados gráficos alocando os alunos nos seguintes grupos: (i) trabalham; (ii) não trabalham nem empreendem; (iii) trabalham e empreendem e, por fim, (iv)empreendem. $\mathrm{O}$ primeiro representa os estudantes com apenas emprego formal, o segundo com emprego formal e atividade empreendedora, o terceiro nenhum dos dois e o quarto apenas atividade empreendedora. Conforme mencionado na introdução do artigo, após esse mapeamento inicial o objetivo é dar continuidade à pesquisa, com a classificação dos negócios e realização de pesquisa de natureza qualitativa com os alunos que desenvolvem projetos ou criaram negócios de base tecnológica com objetivos de contribuição social ou ambiental.

\section{ANÁLISE E DISCUSSÃO DOS RESULTADOS}

Conforme posto no item sobre a metodologia do trabalho, o objeto de pesquisa foram os alunos do ICEG - Instituto de Ciências Econômicas e Gerenciais de uma universidade privada comunitária em Belo Horizonte, Minas Gerais.

Tabela 1 - Dados iniciais dos alunos pesquisados na universidade privada comunitária

\begin{tabular}{|c|c|c|c|}
\hline Alunos & Administração & Economia & Ciências Contábeis \\
\hline \multicolumn{4}{|l|}{ Turno } \\
\hline Matutino & 152 & 85 & 64 \\
\hline Noturno & 94 & 67 & 87 \\
\hline \multicolumn{4}{|l|}{ Faixa Etária } \\
\hline$<18$ & 3 & 1 & 0 \\
\hline $18-29$ & 234 & 140 & 141 \\
\hline $30-39$ & 8 & 8 & 6 \\
\hline $40-49$ & 1 & 3 & 3 \\
\hline $50-59$ & 0 & 0 & 1 \\
\hline$>60$ & 0 & 0 & 0 \\
\hline Participa de atividade empreendedora & 66 & 24 & 28 \\
\hline $\begin{array}{l}\text { Acredita que a universidade incentiva o } \\
\text { empreendedorismo }\end{array}$ & 130 & 66 & 62 \\
\hline
\end{tabular}

Fonte: Dados da pesquisa (2019)

Apresenta-se, no Quadro 1, a distribuição dos alunos pesquisados entre os cursos do referido Instituto e também a sua faixa etária. É possível destacar a grande quantidade de estudantes que se enquadram na faixa etária de 18 a 29 anos, caracterizando um público majoritariamente jovem-adulto. As demais faixas, incluindo as que se situam acima da linha dos 40 anos é consideravelmente menor. Por conseguinte, a quantidade de alunos que participam de atividades empreendedoras representa uma pequena fração daqueles estudantes levantados, o que será abordado em profundidade a seguir. Entretanto, uma extensa parcela dos mesmos acredita que a universidade lhes incentiva a empreender. Cabe destacar, nesse momento, que o estudo não contou com uma definição fixa de empreendedorismo, estando esta sujeita à interpretação dos estudantes. 
Na Figura 3 abaixo são representados os dados para a totalidade de estudantes e a condição geral em que se apresentaram. Podemos observar o contraste entre o número de estudantes que apenas trabalham ( 234 ou $42,62 \%)$ e os que apenas empreendem ( 27 ou $4,92 \%)$, mostrando a prevalência de atividade assalariada nos universitários pesquisados. Esse fato é representado também pela quantidade daqueles alunos que trabalham e também empreendem (91 ou 16,58\%). Outro dado a ser considerado é a quantidade de estudantes que não possuem fonte de renda, seja por meio de salário ou empreendimento, uma vez que cerca de 35,88\% (91) dos alunos não trabalham nem empreendem. Ou seja, aproximadamente um terço dos alunos pesquisados são totalmente dependentes da estrutura financeira familiar.

Figura 3 - Condição do aluno, por turno e noturno

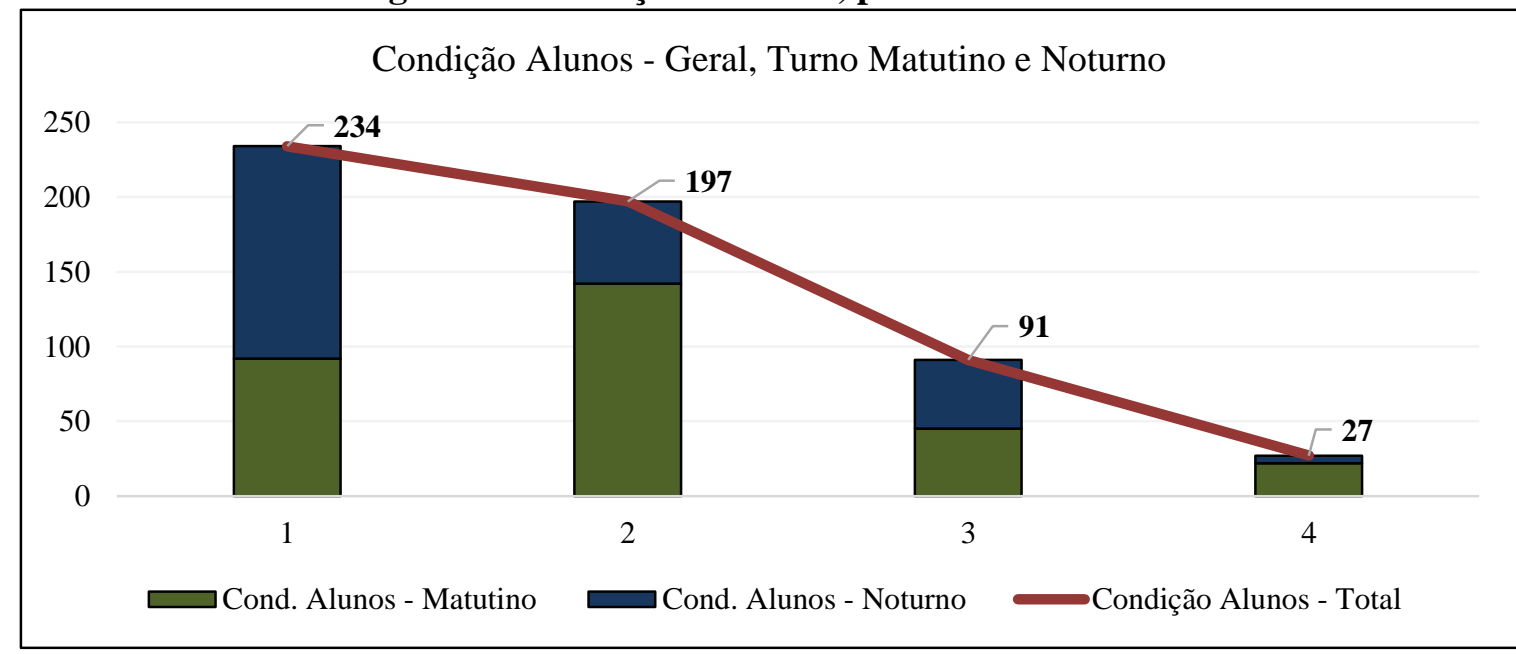

Fonte: Dados da pesquisa (2019)

Ainda analisando a figura anterior, constata-se que 47,18\% dos alunos do turno matutino não possuem emprego formal ou atividade empreendedora, diferentemente dos apenas $22,18 \%$ do noturno. Entretanto, quando o assunto é a quantidade dos alunos com atividade assalariada, o efeito se inverte. O turno matutino possui 30,56\% dos alunos trabalhando e o noturno 57,26\%. No caso específico de desenvolvimento de atividades empreendedoras pelos alunos pesquisados, constatou-se um empreendedorismo maior por parte do período da manhã, onde $7,3 \%$ empreendendo e 14,96\% trabalhando e empreendendo. O período da noite apresentou $2,01 \%$ empreendendo e $18,55 \%$ trabalhando e empreendendo.

Ao realizar comparação entre os cursos pesquisados, percebe-se que os alunos do curso de Administração foi o que apresentou a maior porcentagem de alunos empreendedores. Além disso, o curso de Economia apresentou a maior porcentagem de alunos que não trabalham nem empreendem e o de Ciências Contábeis a maior porcentagem de alunos com apenas o emprego formal. A Figura 4 apresenta a comparação entre a condição dos alunos dos três cursos do ICEG. 
Figura 4 - Condição dos alunos pesquisados quanto ao trabalho formal ou empreendedorismo

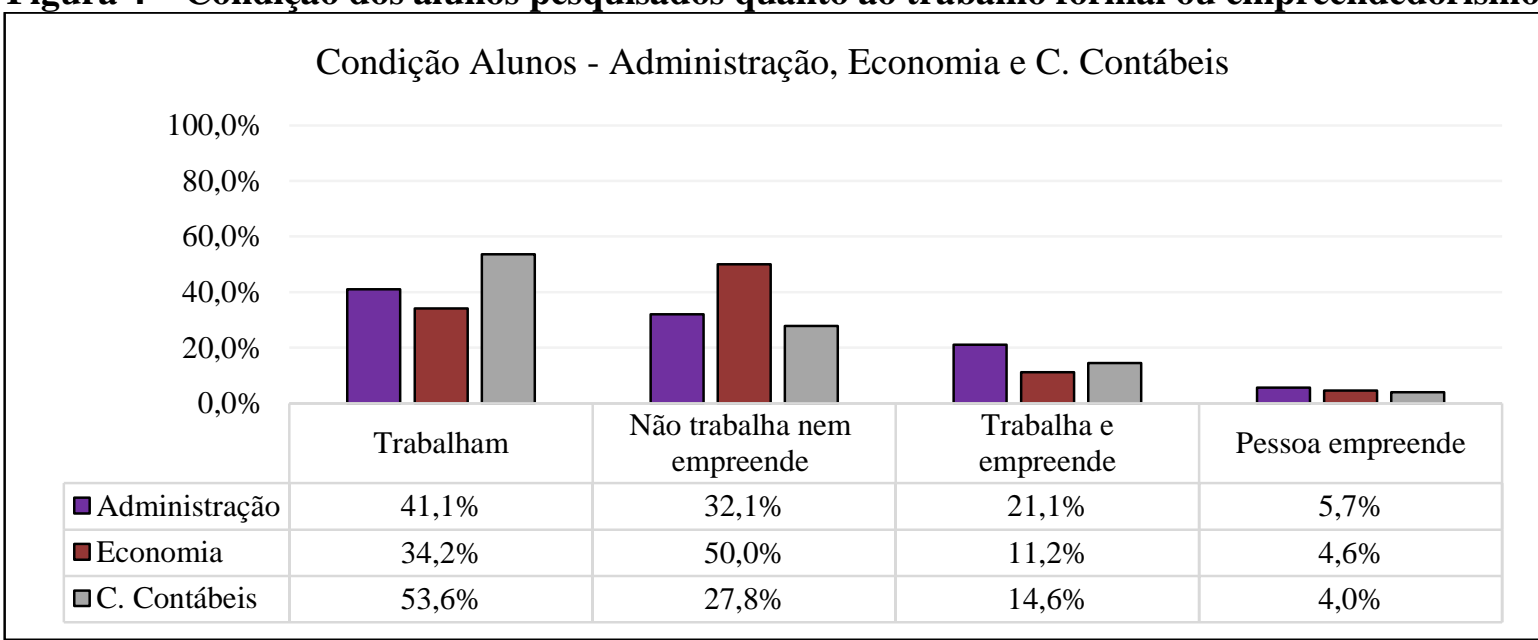

Fonte: Dados da pesquisa (2019)

Com os dados obtidos também foi feita uma tabela de classificação entre as atividades empreendedoras dos alunos. Na Tabela 2, poderá ser visualizada a divisão dos empreendimentos citados pelos alunos em sete categorias: indústria, startup, comércio de produtos, comércio de serviços, ONG, agricultura e outros/não identificados. A última categoria é representada por atividades empreendedoras não identificadas que foram citadas pelos pesquisados, como por exemplo, "empresa do pai", e atividades que não se enquadravam em nenhuma categoria, como por exemplo, "empresa júnior", que não se caracteriza como atividade empreendedora. Além disso, cada atividade foi identificada como social, ambiental, social e ambiental ou nenhum, classificação feita a partir da interpretação dos alunos que responderam à pesquisa. $\mathrm{O}$ valor total de 120 é diferente do apresentado na Figura 3, devido a presença de estudantes que estão em mais de 1 categoria ao mesmo tempo.

Tabela 2. - Categorias dos empreendimentos

\begin{tabular}{lcccccccc}
\hline Categoria: & Indústria & Startup & $\begin{array}{c}\text { Comércio } \\
\text { de } \\
\text { produtos }\end{array}$ & $\begin{array}{c}\text { Comércio } \\
\text { de } \\
\text { serviços }\end{array}$ & ONG & Agricultura & $\begin{array}{c}\text { Outros/Não } \\
\text { identificados }\end{array}$ & TOTAL \\
\hline Social & 1 & 1 & 9 & 9 & 1 & 0 & 4 & 25 \\
Ambiental & 1 & 0 & 2 & 0 & 0 & 1 & 1 & 5 \\
$\begin{array}{l}\text { Social e } \\
\text { Ambiental }\end{array}$ & 0 & 1 & 3 & 0 & 0 & 0 & 0 & 4 \\
Nenhum & 2 & 0 & 41 & 15 & 0 & 2 & 26 & 86 \\
Total & 4 & 2 & 55 & 24 & 1 & 3 & 31 & 120 \\
\hline
\end{tabular}

Fonte: Dados da pesquisa (2019)

Os dados apresentados no quadro 2 permite observar a prevalência de empreendimentos nas categorias de comércio de produtos e/ou serviços - tendência já percebida em cenário nacional, como estabelecimentos de empresas de alimentação e comércio de artigos de 
vestuário (GEM, 2016) - assim como aqueles que não foram identificados. Esse grande valor indica que muitos alunos não especificaram de forma clara a categoria a qual o seu empreendimento poderia estar relacionado. Dado a dificuldade em se estabelecer a definição de empreendedorismo (Shane, 2000), as respostas estiveram sujeitas à interpretação individual e à amplitude de possibilidades de negócios nos quais os alunos pesquisados estão envolvidos.

Como consequências dessa amplitude, foram citadas como atividades empreendedoras a participação em atividades universitárias, como empresas júniores (3\%); emprego em empresa familiar (7\%) e empregos formais (3\%) - categorias que poderiam figurar como exemplos de intraempreendedorismo -, e aplicações e investimentos no mercado financeiro (7\%). Além disso, existe uma parcela considerável de atividades empreendedoras constantemente classificadas como informais e com objetivo de complementação de renda - empreendedorismo por necessidade, geralmente de baixo impacto (Global Entrepreneurship Monitor [GEM], 2016) - como a venda de produtos alimentícios sem ponto fixo.

É possível perceber também o baixo número de negócios classificados como startups ou empreendimentos de base tecnológica. Tal situação reforça o já relatado pequeno número de empreendimentos de alto impacto no território nacional, uma vez que grande parte dos indivíduos tem dificuldades em conceber e implementar negócios dessa natureza (Inácio Júnior et al., 2016), seja por consequências do mercado e regulação nacional (Arruda et al., 2015), ou falta de apoio das universidades (SEBRAE, 2016).Utilizando-se da Tabela 2 acima, foi elaborada a Figura 5, posta a seguir.

Figura 5 - Categorias dos empreendimentos levantados e o posicionamento social e/ou ambiental dos mesmos

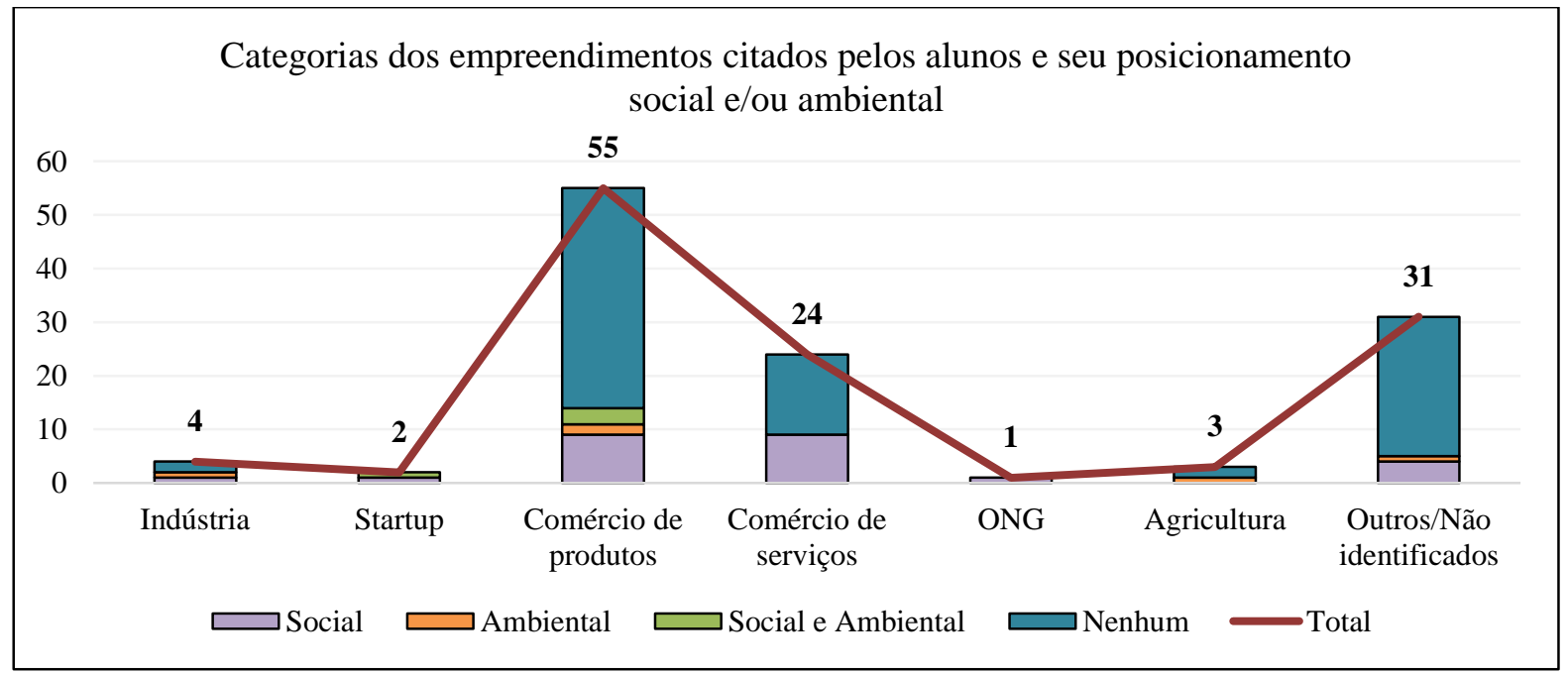

Fonte: Dados da pesquisa (2019)

Ao observar a Figura 5, constata-se que grande parte das atividades empreendedoras não possui caráter social ou ambiental. Entretanto, existe uma porção significativa de empreendedores que classificam seus empreendimentos como tendo característica social. Segundo os próprios entrevistados, o caráter social de suas atividades empreendedoras estaria vinculado ao bem-estar e melhora de autoestima, também classificado pelos pesquisados como possibilidade de "mudança de vida" do possível cliente. Essa percepção acaba por transformar o caráter social das atividades empreendedoras em algo próximo ao discurso de venda, 
distanciando-o da missão "explícita e central” (Dees, 1998, p.3) dos empreendedores sociais. Uma situação semelhante se repete naquelas atividades empreendedoras consideradas de caráter ambiental. As justificativas para a resposta citam, em sua maioria, aspectos de responsabilidade ambiental, atualmente em voga pelas organizações ao redor do mundo (Gast et al., 2017), como preocupações em reciclagem e reutilização. A menção a oportunidades que geram valor ecológico e social são menos frequentes.

Partindo-se do processo convergente para a formação de empreendimentos sustentáveis (Belz \& Binder, 2015), é possível perceber ainda uma maior preocupação dos estudantes em se desenvolver soluções econômicas, e posteriormente ecológicas e sociais. O enfoque maior em soluções que visem o ganho econômico é comum no empreendedorismo e acaba se tornando uma barreira ao empreendedorismo sustentável (Pacheco et al., 2010), que deveria partir do pressuposto de reconhecimento de problemas ecológicos e sociais (Belz \& Binder, 2015). O que ocorre, em um primeiro momento, parece ser o reconhecimento das oportunidades econômicas e a posterior apropriação do discurso social/ambiental para fortalecimento das características econômicas da solução. Tal fato torna mais complexa a geração de soluções double e triple bottom line, que deveriam atuar em conjunto (Belz \& Binder, 2015; Clifford \& Dixon, 2007).

Como o reconhecimento de problemas ecológicos e sociais ao início do processo parecem não serem usuais aos empreendimentos levantados, a exploração de oportunidades nesse ambiente é diminuída, assim como a criação e entrada em mercados sustentáveis. Essa percepção também é fundamentada no baixo número de negócios que aplaquem imperfeições de mercado, como externalidades negativas (Cohen \& Winn, 2007). O estímulo ao empreendedorismo sustentável parece ser então crucial, uma vez que poderá aumentar o impacto das ações empreendedoras e explorar o aspecto intrínseco das atitudes socioambientais de seus empreendedores, mas também tornar possível a atuação dessas organizações na geração de grupos atuantes na sociedade, que busquem a mudança das normas e culturas vigentes (Pacheco et al., 2010).

Como questão final do instrumento de medição apresentado aos estudantes, foi questionado aos mesmos se a universidade que faz parte da pesquisa incentiva o empreendedorismo. Os resultados podem ser visualizados na Figura 6. 
Figura 6 - Incentivo da universidade ao empreendedorismo e os períodos dos cursos

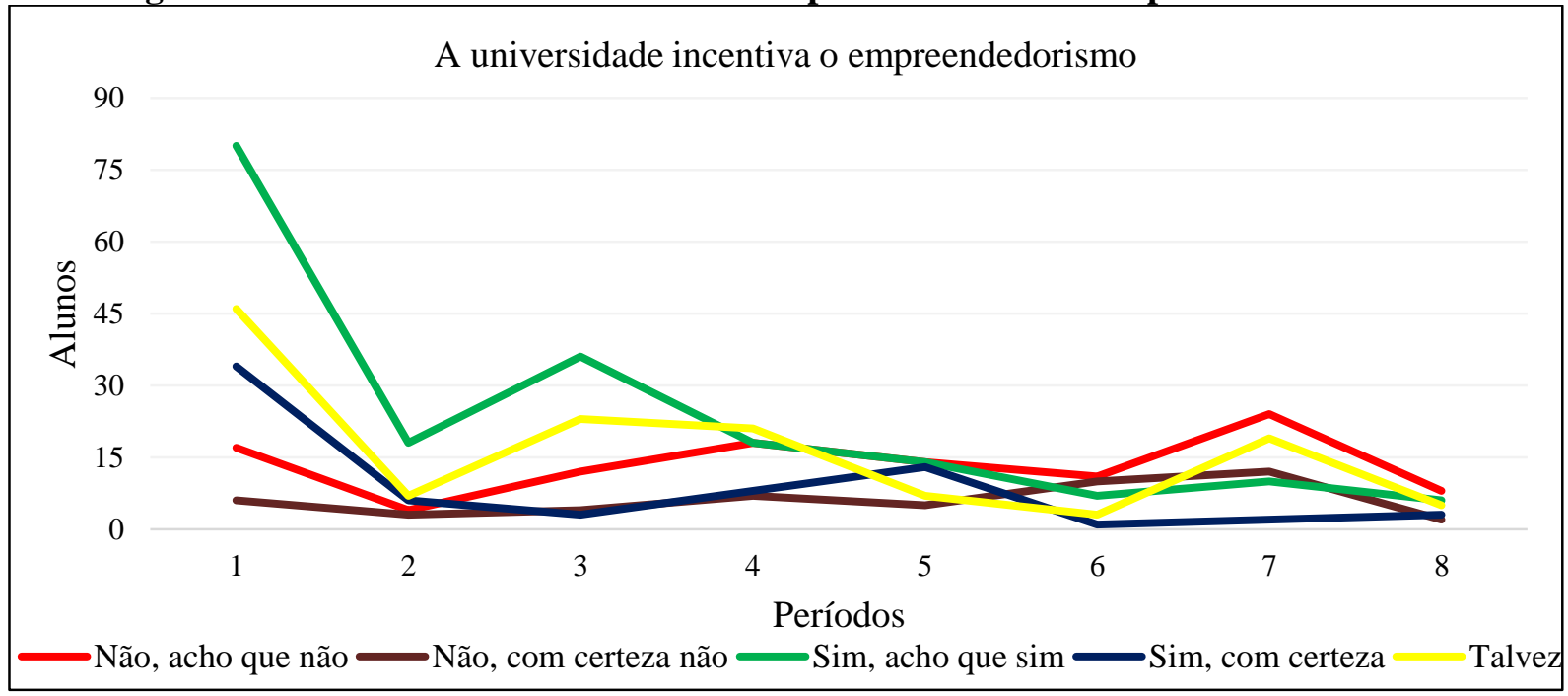

Fonte: Dados da pesquisa (2019)

Sem considerar a distribuição dos estudantes nos períodos dos cursos analisados constata-se a inversão das opiniões positivas e negativas no decorrer da vida universitária dos alunos. Inicialmente, os estudantes dos períodos iniciais acreditam que a universidade lhes incentiva ao empreendedorismo, com alguma ressalva - "sim, acho que sim" e evitam a resposta extrema contrária - "não, com certeza não" -, que aparece em baixo número. Entretanto, uma das opções antagônicas cresce ao decorrer dos períodos e a ganha proeminência - "não, acho que não".

Os números demonstram de forma visual o desafio das universidades em promoverem o empreendedorismo e dialogarem com a percepção dos alunos sobre os cursos e treinamentos oferecidos (Chen et al., 2015; SEBRAE, 2016), uma vez que atividades dinâmicas e que zelem pela postura empreendedora são requisitadas pelos estudantes, mas não difundida nos cursos de graduação (Gibb, 2002; Salume et al,, 2019). Além disso, a própria procura por conhecimentos empreendedores pelos estudantes parece ausente (Salume et al., 2019) e a oferta de serviços e estudos complementares por atores privados externos aos alunos que anseiam por tais conhecimentos aumentam a dificuldade de avaliação por meio dos estudantes (Moreira-Silva et al., 2019).

\section{CONSIDERAÇÕES FINAIS}

A busca por um ambiente mais empreendedor em território nacional passa pela formação empreendedora nas universidades. Entretanto, o Brasil ainda patina nos indicadores de empreendedorismo universitário, onde uma pequena parcela das universidades atua no ensino do empreendedorismo e, muitas vezes, quando atuantes, as avaliações dos estudantes demonstram ser negativas (Chen et al., 2015; Moreira-Silva et al., 2019; SEBRAE, 2016). O levantamento inicial conduzido junto aos potenciais empreendedores e empreendedores que são alunos do Instituto de Ciências Econômicas e Gerenciais de uma universidade privada comunitária demonstra que a atuação da universidade merece sim ser alvo de indagações e maiores pesquisas. 
Os dados mostraram que os estudantes pesquisados apresentam, em sua ampla maioria, uma faixa etária entre 18 e 29 anos. Essa faixa etária pode ser visualizada no perfil do jovem universitário empreendedor em potencial - 25 anos, em média (SEBRAE, 2016). Além disso, os estudantes que frequentam a graduação no período noturno apresentam, em maior frequência, vínculo com atividades formais remuneradas, enquanto uma parcela maior do turno matutino empreende. Ressalta-se, porém, que uma grande parcela dos alunos do turno matutino não trabalha e também não empreende, sendo dependentes da renda familiar.

No caso dos alunos que empreendem, as atividades relacionadas ao comércio de produtos e/ou prestação de serviços são predominantes. Essa condição é semelhante ao encontrado no empreendedorismo em nível nacional (GEM, 2016), inferindo-se que são negócios que apresentam poucas barreiras à entrada, o que acaba por não exigir dos empreendedores alto volume de capital e outros recursos. Ainda sobre os empreendimentos identificados na pesquisa, cabe destacar que a grande maioria desses empreendimentos também não possui caráter social ou ambiental. Ademais, aqueles que possuem, aparentam possuir objetivos de caráter mais econômico que social/ambiental (Belz \& Binder, 2015; Dees, 1998), incorporando-os muitas vezes ao discurso de venda. Cabe ressaltar que o questionário não possuía uma definição fixa de empreendedorismo, estando às respostas sujeita à percepção do respondente sobre o seu próprio negócio.

No que diz respeito à atuação e apoio da universidade no incentivo ao empreendedorismo, as respostas variaram conforme os estudantes avançam em seu curso de graduação. Nos primeiros períodos, um grande número dos alunos acredita que a universidade lhes incentiva a empreender, percepção que entra em declínio e se inverte em percepção negativa, já ao fim do curso, onde os alunos acreditam que a universidade não os incentiva a empreender. Esses dados, sobretudo, demonstram a dificuldade no alinhamento de expectativas entre os alunos que desejam a formação empreendedora, corpo docente e a instituição universitária (Moreira-Silva et al., 2019; Salume et al., 2019).

Por fim, os resultados iniciais sobre as atividades empreendedoras dos alunos tratados nesse artigo possibilitam indicar a ampliação de pesquisas relativas às iniciativas de criação do próprio negócio dos discentes, assim como o aprofundamento na compreensão dessas iniciativas, de forma que a coordenação de cursos semelhantes - ciências sociais aplicadas consiga refletir e desenvolver estratégias de fomento e fortalecimento do empreendedorismo entre os jovens graduandos.

\section{REFERÊNCIAS}

ABStartups. (2017). Tudo que você precisa saber sobre startups. Recuperado a partir de: https://abstartups.com.br/2017/07/05/o-que-e-uma-startup/. Acesso em: 29 de outubro de 2018 Arruda, C.; Nogueira, V. S.; Cozzi, A.; Costa, V. (2015). The brazilian entrepreneurial ecosystem of startups: an analysis of entrepreneurship determinants in Brazil and the perceptions around the brazilian regulatory framework. Entrepreneurship in BRICS. 9-25. Recuperado a partir de: https://link.springer.com/chapter/10.1007/978-3-319-11412-5_2

Belz, F. M.; Binder, J. K. (2015). Sustainable entrepreneurship: a convergente process model. Business Strategy and the Environment, 1-17.

Blank, S. (2010). What's a startup? First principles. Recuperado a partir de: https://steveblank.com/2010/01/25/whats-a-startup-first-principles/

Boehm, C. (2018). Consumo de recursos naturais superou o que o mundo pode renovar no ano. Recuperado a partir de: http://agenciabrasil.ebc.com.br/geral/noticia/2018-08/consumo-de- 
recursos-naturais-superou-que-o-planeta-pode-renovar-no-ano. Acesso em: 07 de novembro de 2018

Bosma, N., \& Kelley, D. (2019). Global Entrepreneurship Monitor 2018/2019 Global Report. Babson Park: Global Entrepreneurship Research Association.

Boszczowski, A. K., \& Teixeira, R. M. (2012). O empreendedorismo sustentável e o processo empreendedor: em busca de oportunidades de novos negócios como solução para problemas sociais e ambientais. Revista Economia \& Gestão, 12(29), 141-168.

Boutillier, S. (2017). Small entrepreneurship, knowledge and social resources in a heavy industrial territory. The case of eco-innovations in Dunkirk, north of France. Journal of Knowledge Economy, 1-22.

Brito, D. (2018). Startups crescem no Brasil e consolidam nova geração de empreendedores. Recuperado a partir de: http://agenciabrasil.ebc.com.br/economia/noticia/2018-07/startupscrescem-no-brasil-e-consolidam-nova-geracao-de-empreendedores. Acesso em: 29 de outubro de 2018

Chen, S.; Hsiao, H.; Chang, J.; Chou, C.; Chen, C.; Shen, C. (2015). Can the entrepreneurship course improve the entrepreneurial intentions of students? International Entrepreneurship Management Journal, 11, 557-569. Recuperado a partir de: https://link.springer.com/article/10.1007\%2Fs11365-013-0293-0

Coelho, P. S., \& da Silva, R. N. S. (2007). Um estudo exploratório sobre as metodologias empregadas em pesquisas na área de contabilidade no EnANPAD. Revista contemporânea de contabilidade, (8), 139-159.

Cohen, B.; Winn, M. I. (2007). Market imperfections, opportunity and sustainable entrepreneurship. Journal of Business Venturing, 22, 29-49.

Dees, J. G. (1998). The meaning of "Social Entrepreneurship". Recuperado a partir de: http://www.redalmarza.cl/ing/pdf/TheMeaningofsocialEntrepreneurship.pdf

Dias, A. A. S., \& de Oliveira Dias, M. A. (2017). Educação ambiental. Revista de Direitos Difusos, 68(1), 161-178.

Dixon, S. E. A.; Clifford, A. (2007). Ecopreneurship - a new approach to managing the triple bottom line. Journal of Organisational Change Management, 20 (3). 326-345.

Figueira, K. K., Hörbe, T. D. A. N., Vargas, K. D. F. S., Machado, E. C., \& de Moura, G. L. (2017). Startups: estudo do processo de abertura e gerenciamento. Revista de Administração da Universidade Federal de Santa Maria, 10, 56-71.

Ganotakis, P. (2012). Founders' human capital and the performance of UK new technology based firms. Small Business Economics, 39, 495-515. Recuperado a partir de: https://link.springer.com/article/10.1007/s11187-010-9309-0

Gast, J., Gundolf, K., \& Cesinger, B. (2017). Doing business in a green way: A systematic review of the ecological sustainability entrepreneurship literature and future research directions. Journal of Cleaner Production, 147, 44-56.

Genome, S. (2017). Global startup ecosystem report 2017. Startup Genome: San Francisco, CA, USA.

Gil, A. C. (2002). Como elaborar projetos de pesquisa. São Paulo, 5(61), 16-17.

Henrekson, M.; Johansson, D. (2010) Gazelles as job creators: a survey and interpretation of the evidence. Small Business Economics, 35, 227-244. Recuperado a partir de: https://link.springer.com/article/10.1007/s11187-009-9172-z

Hisrich, R. D., Peters, M. P., \& Shepherd, D. A. (2014). Empreendedorismo-9. AMGH Editora. 
Jacobi, P. R. (2003). Educação ambiental, cidadania e sustentabilidade. Cadernos de pesquisa, (118), 189-205.

Kleina, N. (2017). A história e o estouro da bolha da internet do ano 2000. Recuperado a partir de: https://www.tecmundo.com.br/mercado/124475-historia-estouro-bolha-da-internet-ano2000-video.htm. Acesso em: 07 de novembro de 2018

Lago, A., Coronel, D., Lengler, L., \& da Silva, T. (2008). Potencialidades e espaços ao $\begin{array}{llll}\text { empreendedorismo. } & \text { Estudos } & \text { 78-101. }\end{array}$ doi:https://doi.org/10.17058/cepe.v0i27.424

Leite, E. F. (2017). O fenômeno do empreendedorismo. Editora Saraiva.

Machado, F. G. (2015). Investidor Anjo - Uma análise dos critérios de decisão de investimentos em startups. Dissertação de Pós-Graduação, Universidade de São Paulo, São Paulo, SP

Machado, H. P. V. (2018). Crescimento de empresas na perspectiva de pequenos empreendedores de base tecnológica. $R A C, 22(6), 817-840$. Recuperado a partir de: http://www.scielo.br/scielo.php?script=sci_abstract\&pid=S1415-

$65552018000600817 \& \operatorname{lng}=$ pt\&nrm=iso

Monteiro, M. N. L. (2010). O empreendedorismo e a criação de negócios: o caso da empresa. (Master's thesis, FEUC).

Moreira-Silva, J. P.; Guimarães, L. O.; Inácio Júnior, E.; Castro, J. M. de (2019, outubro). Ecossistema empreendedor: análise da contribuição de universidades na criação de empresas de base tecnológica. Anais do Encontro Nacional da Associação Nacional de Pós-Graduação e Pesquisa em Administração, São Paulo, SP, Brasil.

Oliveira, F. (2018). Só $18 \%$ das startups têm como cliente o consumidor final. Recuperado a partir de: https://www1.folha.uol.com.br/mercado/2018/07/so-18-das-startups-tem-comocliente-o-consumidor-final.shtml. Acesso em: 19 de novembro de 2018

Padrão, L. C., \& Andreassi, T. (2013). O desempenho de startups de base tecnológica: um estudo comparativo em regiões geográficas brasileiras. Revista da Micro e Pequena Empresa, 7(2).

Paiva, L. E. B., de Lima, T. C. B., Rebouças, S. M. D. P., Ferreira, E. M. D. M., \& Fontenele, R. E. S. (2018). Influência da sustentabilidade e da inovação na intenção empreendedora de universitários brasileiros e portugueses. Cadernos EBAPE. BR, 16(4), 732-747.

Pinochet, L. H. C., de Souza, I., Lopes, E. L., \& Bueno, R. L. P. (2018). Fatores antecedentes da tomada de decisão na criação de startups na perspectiva de jovens estudantes universitários. Revista da Micro e Pequena Empresa, 12(1), 33.

Plonsky, G. A. (1999). Cooperação universidade-empresa: um desafio gerencial complexo. Revista de Administração, 34(4), 5-12. Recuperado a partir de: 200.232.30.99/download.asp?file=3404005.pdf

Premand, P.; Brodmann, S.; Almeida, R.; Grun, R.; Barouni, M. (2016). Entrepreneurship education and entry into self-employment among university graduates. World Development, 77 , 311-327. Recuperado a partir de: http://documents.worldbank.org/curated/en/205601468334874186/pdf/wps6285.pdf

Rosa, B. (2018). Taxa de mortalidade de start ups chega a 75\%. Recuperado a partir de: https://oglobo.globo.com/economia/taxa-de-mortalidade-de-start-ups-chega-75-22695381.

Recuperado a partir de: 07 de novembro de 2018.

Salume, P. K.; Guimarães, L. O.; Junqueira, L. R.; Rodrigues, T. M. (2019, agosto). Universidade empreendedora: análise de estruturas e iniciativas de estímulo ao 
empreendedorismo no ensino superior. Anais do Encontro Nacional de Cursos de Graduação em Administração, Uberlândia, MG, Brasil.

Sarkar, S. (2010). Empreendedorismo e inovação. Escolar Editora.

Saxenian, A. (1990). Regional Networks and the resurgence of Silicon Valley. California Management Review. 89-109. Recuperado a partir de: http://www1.ximb.ac.in/users/fac/visiting/vfac.nsf/23e5e39594c064ee852564ae004fa010/51e 213743b63ce6e65257028003e3ccc/\$FILE/saxenian.pdf

Serviço Brasileiro de Apoio às Micro e Pequenas Empresas (2016). Empreendedorismo nas universidades brasileiras. Recuperado a partir de: http://www.sebrae.com.br/sites/PortalSebrae/artigos/o-empreendedorismo-nas-universidadesbrasileiras,6ad3352450608510VgnVCM1000004c00210aRCRD

Serviço Brasileiro de Apoio às Micro e Pequenas Empresas. (2017). Startups mineiras investem em negócios de impacto social e ambiental. Recuperado a partir de: https://revistapegn.globo.com/Tecnologia/noticia/2017/12/startups-mineiras-investem-emnegocios-de-impacto-social-e-ambiental.html?fbclid=IwAR3zgNbdIrMq8soPJQ-

TVr8J4eAzrk8IFKbGAH6VaC86gotQhLX8i8hPGQk. Acesso em: 07 de novembro de 2018 Serviço Brasileiro de Apoio às Micro e Pequenas Empresas (2016). Empreendedorismo nas universidades brasileiras. Recuperado a partir de: https://m.sebrae.com.br/Sebrae/Portal\%20Sebrae/Anexos/Relatorio\%20Endeavor\%20impress ao.pdf

Tornatzky, L. G.; Rideout, E. C. (2014). Innovation U 2.0: reinventing university roles in a knowledge economy. Recuperado a partir de: http://www.innovation-u.com/InnovU-2.0_rev12-14-14.pdf.

Varrichio, P. C. (2016). Uma discussão sobre a estratégia de inovação aberta em grandes empresas e os programas de relacionamento voltados para startups no Brasil. Revista de Administração, Contabilidade e Economia da Fundace, 7(1).

World Bank Institute (2019). Building knowledge economies: advances strategies for development.

Recuperado

a partir

de:

http://siteresources.worldbank.org/KFDLP/Resources/461197-

1199907090464/BuildingKEbook.pdf

Yin, R., K. (2005). Projetando estudos de caso. In Yin (2005), Estudo de caso: planejamento e método (p. 39-79). Porto Alegre: Bookman. 